
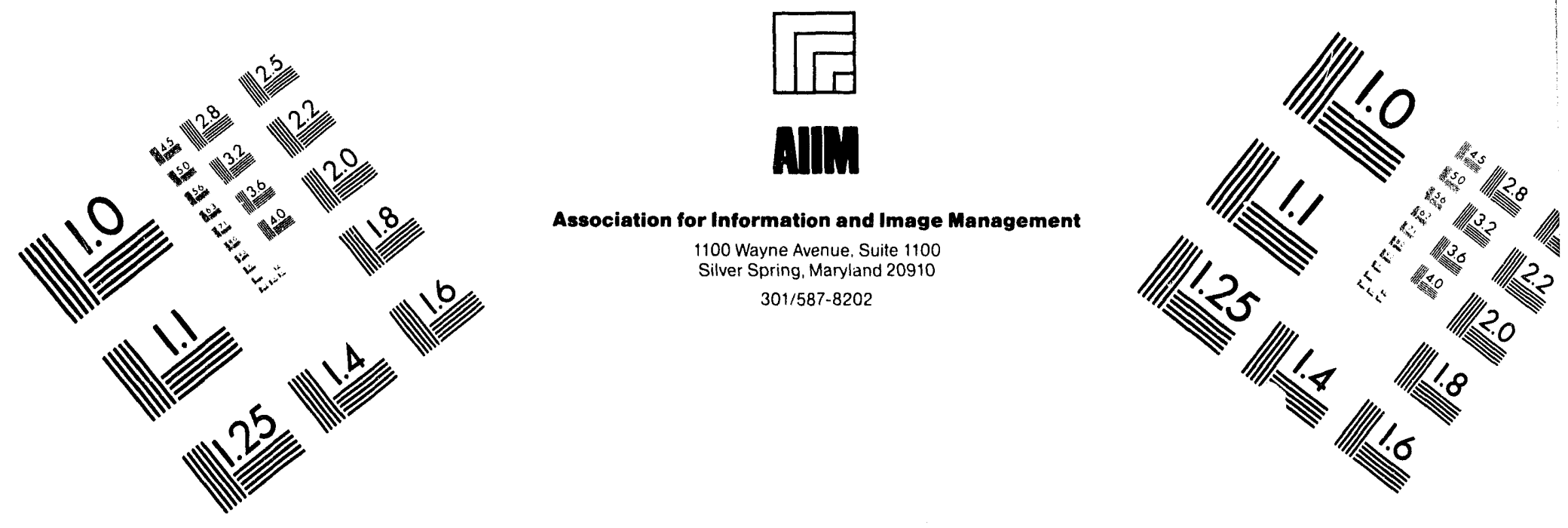

\title{
Centimeter
}

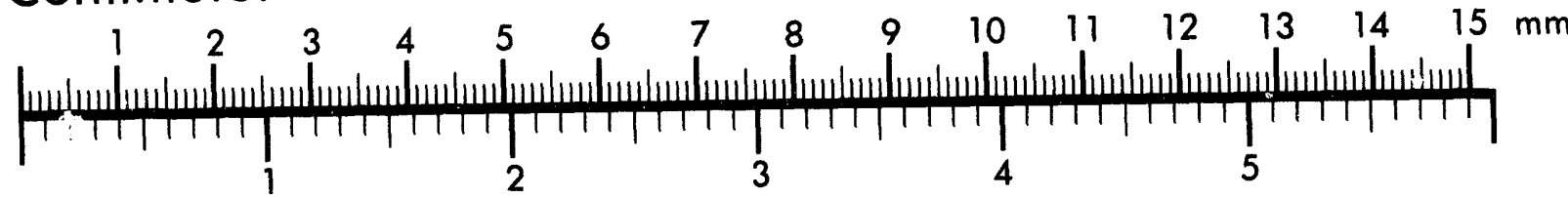
Inches
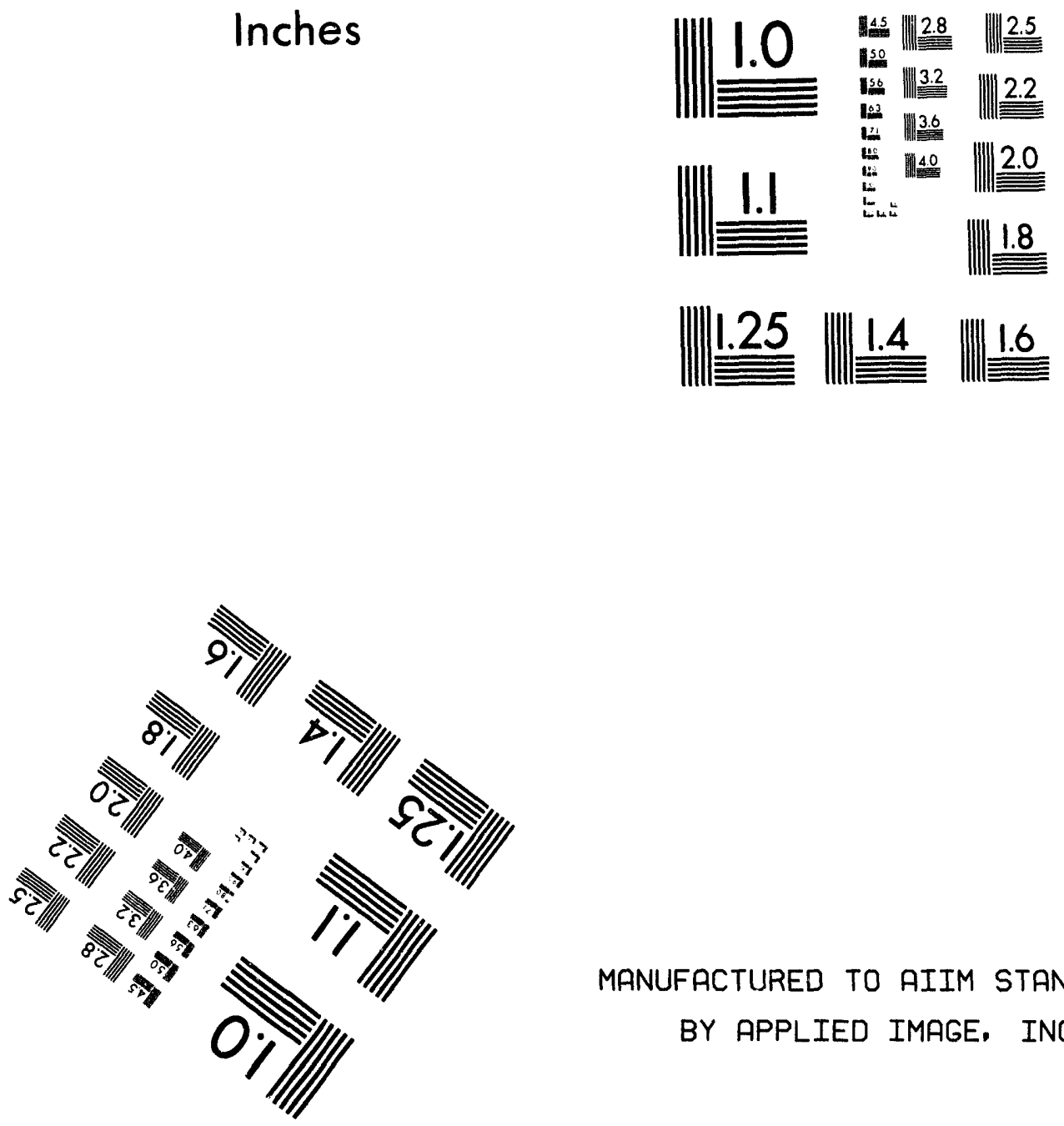

MANUFACTURED TO AIIM STANDARDS

BY APPLIED IMAGE, INC.

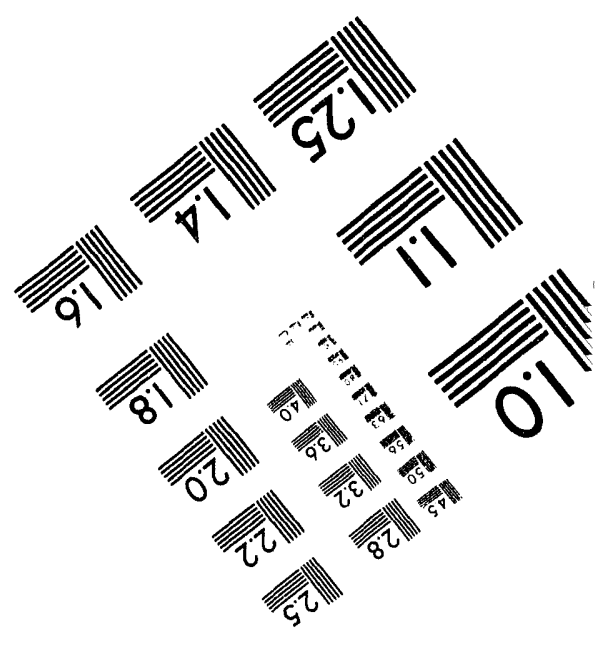



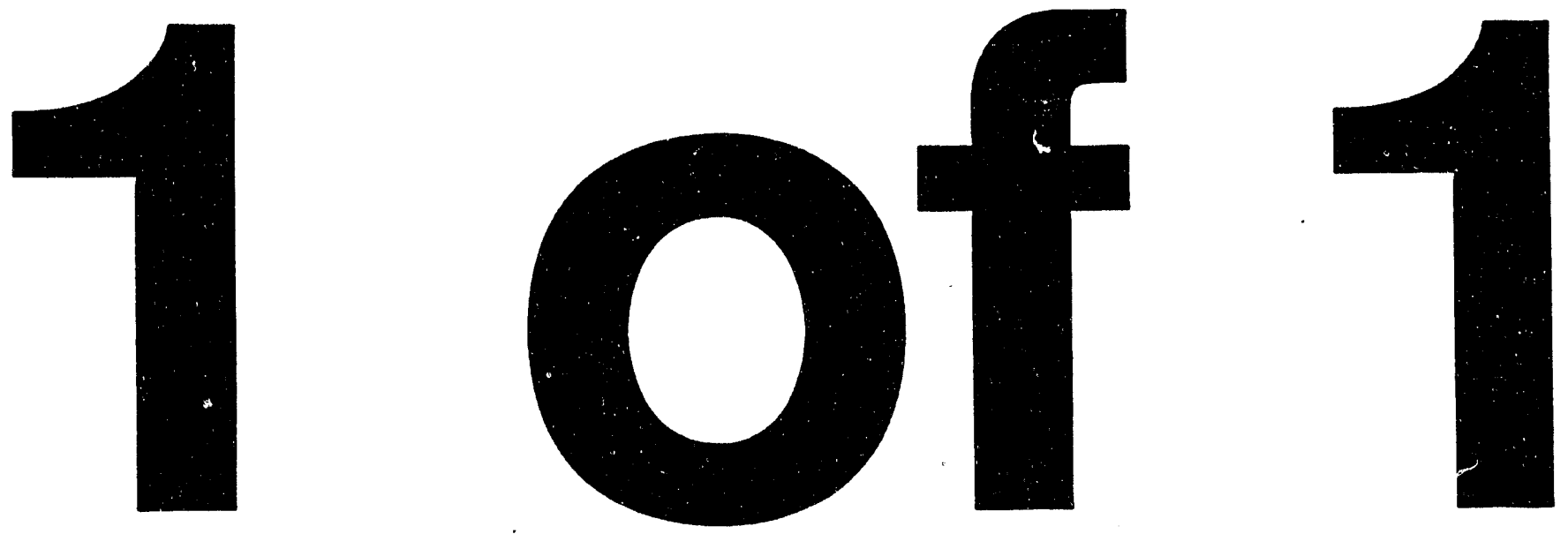


\section{FATALITY RISK ESTIMATION FOR REPLACEMENT TRITIUM FACILITY}

by

Kim, K. S.

Westinghouse Savannah River Company

Savannah River Site

Aiken, South Carolina 29808

DOE Contract No. DE-AC09-89SR18035

This paper was prepared in connection with work done under the above contract number with the U. S.

Department of Energy. By acceptance of this paper, the publisher and/or recipient acknowledges the U. S. Government's right to retain a nonexclusive, royalty-free license in and to any copyright covering this paper, along with the right to reproduce and to authorize others to reproduce all or part of the copyrighted paper.

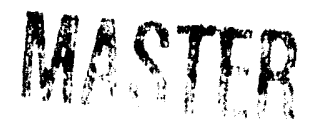




\section{DISCLAIMER}

This report was prepared as an account of work sponsored by an agency of the United States Government. Neither the United States Govemment nor any agency thereof, nor any of their employees, makes any warranty, express or implied, or assumes any legal liability or responsibility for the accuracy. completeness, or usefulness of any information, apparatus, product, or process disclosed, or represents that its use would not infringe privately owned rights. Reference herein to any specific commercial product, process, or service by trade name, trademark, manufacturer, or otherwise does not necessarily constitute or imply its endorsement, recommendation, or favoring by the United States Government or any agency thereof. The views and opinions of authors expressed herein do not necessarily state or reflect those of the United States -Government or any agency thereof.

This report has been reproduced directly from the best available copy.

Available to DOE and DOE contractors from the Office of Scientific and Technical Information. P. O. Box 62, Oak Ridge. TN 37831: prices available from (615) $576-8401$

Available to the public from the National Technical Information Service, U. S. Department of Commerce. 5285 Port Royal Rd.. Springfield, VA 22161 
Document Number: WSRC-TR-94-0356

Document Title: Fatality Risk Estimation for Replacement Tritium Facility (U)

Author: K. S. Kim

Technical Reviewer: R. F. Bradley

Key Words: Nuclear Safety Goals

Replacement Tritium Facility

Prompt Fatality

Cancer Fatality

Exceedance Probability 


\title{
TABLE OF CONTENT
}

\author{
Abstract---1 \\ Introduction---2 \\ Summary of FSAR and Data Adjustment---3 \\ Prompt Fatality Risk----4 \\ Latent Cancer Fatality----4 \\ Uncertainty---5 \\ Conclusion----6 \\ References---7 \\ TABLES \\ FIGURES
}


Fatality Risk Estimation for Replacement Tritium Facility (U)

\author{
K.S. Kim \\ Westinghouse Savannah River Company \\ Aiken, South Carolina, 29802
}

\begin{abstract}
[Abstract]
Prompt and latent cancer fatality risks are estimated in this report for the operation of the Replacement Tritium Facility (RTF) at the Savannah River Site (SRS). The purpose of this report is to demonstrate that : 1) the calculated fatality risk for the RTF operation is well within the quantitative Nuclear Safety Goals established by the Department of Energy (DOE) and 2) a simple point estimate method can produce results comparable to those of more detailed calculation utilizing computer codes and protocols developed for Probabilistic Risk Assessment (PRA) of nuclear power reactors.

Point estimates of prompt and cancer fatality risks are performed using a simple mathematical formalism derived from the complementary cumulative distribution function (CCDF) of consequences. The protocol of establishing CCDF is based on a successive summation of event frequencies. The consequences (i.e., calculated individual radiation doses at site boundary) and associated event frequencies are available from the RTF Final Safety Analysis Report (FSAR).

The results indicate that calculated prompt fatality and cancer fatality risks due to RTF operation are 0 and $1.5 \times 10^{-9} / \mathrm{yr}$, respectively, well below the DOE's Safety Goals of $5 \times 10^{-7} / \mathrm{yr}$ (prompt fatality) and $2 \times 10^{-6} / \mathrm{yr}$ (cancer fatality). The agreement between the point estimate method and the PRA method is very good considering the differences in assumptions between the two methods (i.e., additional earthquake-induced scenarios).
\end{abstract}




\section{Introduction}

The RTF is designed and constructed to replace the existing tritium loading facilities at the SRS. A detailed description of the RTF design and operation is presented in the FSAR ${ }^{1}$. The FSAR also presents analyses of various postulated accident scenarios in terms of radiological consequences (e.g., maximum individual doses or MIDs) and associated event frequencies as well as the consequence of normal operation. The analyses in FSAR are, in principle, deterministic analyses of selected discrete accident scenarios using computer codes AXAIR89Q ${ }^{2}$ for radiological dose calculation and CAFTA ${ }^{3}$ for frequency estimation. The results are point estimates of radiation doses and frequencies for discrete accident events. These point estimates are not directly comparable to the DOE's Nuclear Safety Goals defined in terms of total fatality risks from all accidents to an average individual at the site boundary and within 10 miles from that site boundary ${ }^{4}$. In order to estimate the radiological risk comparable to the DOE's Nuclear Safety Goals, an additional probabilistic risk analysis using sucn computer codes as MACCS and FUSCRACK3 was performed recently ${ }^{5}$.

The computer codes, MACCS and FUSCRACK3 have been developed for PRAs of commercial nuclear reactors and these codes require statistically distributed inputs. Therefore, the results of AXAIR89Q and CAFTA (i.e., point estimates) currently available from SARs of nonreactor facilities at SRS can not be directly used for MACCS or FUSCRACK3.

In order to utilize the results of accident analyses typically available in the SARs (i.e., point estimates based on predetermined parameters), a simple mathematical formalism and protocol were proposed in a recent report ${ }^{6}$. In this report, mathematical expression for the estimate of total fatality risk was derived from a complementary cumulative distribution function, CCDF (or simply called annual exceedance probability/frequency) of consequence and its integrals. The protocol for establishing CCDF is based on a successive summation of discrete event frequencies followed by enveloping high points with a straight line (Limit Line). Further details are presented in Reference 6 as an example case analysis. It was shown that total prompt fatality and latent cancer fatality risks comparable with DOE's Nuclear Safety Goals can be calculated from exceedance probabilities of radiation dose [denoted by $\mathrm{P}(>\mathrm{D})$ ] summarized below.

The prompt fatality risk, $F_{p}$ can be expressed as

$$
F_{p}=P\left(>D_{L}\right)
$$

for the case when the dose-response function is a step function (i.e., probability of prompt fatality changes from 0 to 1.0 at $D=D_{L}$ where $D_{L}$ is the lethal dose), or

(2) $\quad F_{p}=\left(\frac{1}{D_{2}-D_{1}}\right) \cdot \int_{D 1}^{D 2} P(>D) \cdot d D$ 
for the case when dose-response function is a linear function between $D_{1}$ and $D_{2}$ (i.e., probability of prompt fatality increase linearly from 0 to 1 between $D_{1}$ and $D_{2}$ ).

The latent cancer fatality risk, $\mathrm{F}_{\mathrm{c}}$ can be calculated by

(3) $\quad F_{c}=K \cdot \int_{0}^{D \max } \mathrm{P}(>\mathrm{D}) \cdot \mathrm{dD}$

where $\mathrm{K}$ is the cancer rate per exposure (i.e., cancer per rem).

The above simple method is used for the calculation of fatality risks due to RTF operation as shown below.

\section{Summary of FSAR and Data Adjustment}

The RTF FSAR presents various discrete accident scenarios and resulting radiation doses to various target individuals and population groups. Additional accident scenarios initiated by Design Basis Earthquakes (DBE) are analyzed recently and reported in the SAR Addendum 7. The individual accident scenarios and normal operation selected for this analysis are summarized in Table I, Frequency and MID columns.

Since the MID values are the maximum individual CEDE (cumulative effective dose equivalent), that is, 50-year cumulative effective dose equivalent to a hypothetical person at the worst sector of the site boundary (maximum individual), the MID values need to be adjusted to represent average acute individual doses at the site boundary and average individual CEDE within 10 miles from the site boundary.

Two factors, meteorological dispersion factor $(\chi / Q)$ and dose accumulation time factor, need to be considered for the adjustment. The adjustment due to $\chi / Q$ differences between the worst sector and average sector can be made by the following equation $\left(m_{1}\right.$ denotes the adjustment factor).

$$
\mathrm{m}_{1}=\frac{\sum_{i, j}\left[(\chi / \mathrm{Q})_{i, j} \times \mathrm{P}_{i, j}\right]}{(\chi / \mathrm{Q})_{\operatorname{MDD}} \times \sum_{i, j}\left(\mathrm{P}_{i, j}\right)}
$$

where $(\chi / Q)_{i j}=\chi / Q$ at distance $i$ and directional sector $j$

$(\chi / Q)_{\mathrm{MID}}=\chi / \mathrm{Q}$ at worst sector of site boundary, and

$\mathbf{P}_{i, j}=$ population in $i, j$-segment.

Using the $\chi / Q$ values and population distribution listed in Table II ${ }^{8}, \mathrm{~m}_{1}$ is calculated to be 0.6 at the site boundary and 0.005 for a 10 mile band from the site boundary. 
The adjustment factor, $\mathrm{m}_{2}$ for conversion of CEDE to acute dose can be expressed by following equation.

$m_{2}=\frac{1-\exp (-0.17 \Lambda)}{1-\exp (-50 \Lambda)}$

where $\Lambda=(\ln 2) / T_{1 / 2}$, and $T_{1 / 2}$ is the effective half life of tritium, which is about 10 days $(0.027 \mathrm{yr})^{9}$. For the purpose of this analysis, acute dose is defined as cumulative dose effect for 60 days $(0.17 \mathrm{yr})$ due to a short term inhalation of tritium. Using the above values, the $m_{2}$ is calculated to be 0.99 , which means that acute dose is about the same as CEDE (i.e., $99 \%$ of CEDE due to a single tritium intake is contributed during the first 60 days).

Using $m_{1}$ and $m_{2}$, the MID values can be converted to acute dose to an average person at the site boundary, and CEDE to average person within 10 miles of the site boundary by multiplying by $0.6(0.6 \times 0.99)$ and $0.005\left(\mathrm{~m}_{1}\right.$ only), respectively. The results are also summarized in Table I. It should be noted that the MID for Normal Operation reported in the FSAR (Event 10 of Table I) is based on annual average $\chi / Q$, hence the adjustment factor for 10 mile average CEDE is 0.5 (ratio of annual average $\chi / Q$ at site boundary and $\chi / Q$ at 10 mile segments).

\section{Prompt Fatality Risk}

From Table I, the exceedance probability of acute dose, $P(>D)$ can be established as shown in Table III and graphically shown in Figure 1 with a Limit Line.

From Figure 1, it is apparent that the prompt fatality risk is 0 (i.e., the integral of equation 1 or 2 is 0 , since the maximum acute dose of about 4 rem is much smaller than $D_{L}$ or $D_{1}$ which is on the order of a few hundred rem ${ }^{10}$ ).

\section{Latent Cancer Fatality}

For the cancer fatality risk, the exceedance probabilities are established using the 10-mile average individual CEDE, and the result is summarized in Table IV and graphically shown in Figure 2 with Limit Line. The cancer fatality risk is calculated by integration of the Limit Line according to Equation (3). Various cancer rates per exposure have been reported in literature, but a cancer rate of $\mathrm{K}=8 \times 10^{-4} / \mathrm{rem}{ }^{11}$ was used in this study for conservatism. In the calculation below, the normal operation includes anticipated operational occurrences (i.e., $\mathrm{P}(>\mathrm{D})=0.01$ or $\mathrm{D}<1.4 \times 10^{-5} \mathrm{rem}$ ). 


$$
\begin{aligned}
F_{c} & =\left(8 \times 10^{-4}\right) \cdot \int_{0}^{0.033} P(>D) \cdot d D \\
& =\left(8 \times 10^{-4}\right) \cdot\left\{\int_{0}^{1.4(-5)} P(>D) \cdot d D+\int_{1.4(-5)}^{0.033} P(>D) \cdot d D\right\} \\
& =\left(8 \times 10^{-4}\right)\left(7.2 \times 10^{-7}+1.1 \times 10^{-6}\right) \\
& =5.8 \times 10^{-10} / \mathrm{yr} \text { (normal operation) }+9.0 \times 10^{-10} / \mathrm{yr} \text { (accident) } \\
& =1.5 \times 10^{-9} / \mathrm{yr} \text { (total) }
\end{aligned}
$$

\section{Uncertainty}

As indicated in the previous sections, the fatality estimation in this report is a deterministic point estimate based on "average values" of consequences and associated frequencies available from existing FSAR. Although "average values" in the FSAR are not rigorously defined from mathematical standpoint (e.g., they varies between mean, median, nominal, and best estimates), they tend to be on the conservative side. Therefore, fatality risk estimates in this report may also be a conservative estimation for the average population. No attempt is made in this report to define the uncertainty associated with the calculated risk, since doing so will reduce the usefulness of the approach taken in this report, which is to make point estimates of fatality risks comparable to DOE's Safety Goals utilizing the results readily available from existing FSAR without utilizing PRA methods.

In a recent presentation by G.T. Medford, et.al. at EFGOG workshop ${ }^{12}$, it was shown that nominal point estimates of frequencies and source terms for a fire scenario agree reasonably well with the mean risk values by MUPPET code with Monte Carlo sampling technique except for the low frequency/high source term extreme range (NOTE: Low frequency-high consequence end of the Limit Line contribute very little to total cancer risk). Several papers by Helton, et.al. 13 indicated that mean or 50 percentile consequence values are reasonable "average" estimates of consequences (i.e., they falls between 5-95 percentile values). Therefore, it is concluded that fatality risk estimates in this report are adequate estimates for the purpose of comparing with DOE's Safety Goals which are defined by point values. 


\section{Conclusion}

Based on the preceding analysis and discussion, it is concluded that the prompt fatality risk and cancer fatality risk due to RTF operation are substantially beiow the DOE's Safety Goals as summarized below.

\begin{tabular}{llll} 
& \multicolumn{1}{c}{ RTF } & & Safety Goal \\
\cline { 2 - 2 } Prompt Fatality & 0 & $5 \times 10^{-7} / \mathrm{yr}$ \\
Latent Cancer Fatality & $1.5 \times 10^{-9} / \mathrm{yr}$ & $2 \times 10^{-6} / \mathrm{yr}$
\end{tabular}

The total cancer fatality risk is about equally contributed from normal operation including anticipated occurrences (40\% of total) and hypothetical accidents (60\% of total).

It should be noted that the analysis in this paper include additional earthquake-induced accident scenarios (events $8 \mathrm{~A}$ through $\mathrm{K} 2$ in Table I), which were not included in the analysis of Reference 5. Furthermore, all the earthquake-induced events are treated as discrete independent events in this report, although the frequency value of initiating event (i.e., earthquake) is clearly an exceedance frequency. Considering the above conservatism, the result in this paper is generally in a good agreement with that of PRA methods presented in Reference 5 (i.e., 0 prompt fatality and $8.7 \times 10^{-10} / \mathrm{yr}$ total cancer fatality). Hence, it is concluded that a simple approach taken in this paper is a useful and economical alternative method to the PRA method for estimation of fatality risks comparable to DOE Safety Goals. 


\section{Reference}

1. Safety Analysis Report for 200 Area Replacement Tritium Facility, WSRC-SA-1-1 (1991)

2. D.M. Hamby, "Verification of the AXAIR89Q Dose Assessment Code", WSRC-RP90-1222, Savannah River Laboratory (1990)

3. CAFTA User's Manual, Science Applications International Inc. (1992)

4. Nuclear Safety Policy, SEN-35-91 (DOE, 1991)

5. K.R. D'Kula \& J.M. East, "RTF Compliance with DOE Safety Goals", WSRC-TR-93183 (1993)

6. K.S. Kim \& R.F. Bradley, "Overall Risk Estimation for Nonreactor Nuclear Facilities and Implementation of Safety Goals", WSRC-TR-93-550 (1993)

7. WSRC-SA-1-1-VOL-19, Rev. 0, FSAR Addendum, Attachment 5.A (1993)

8. WSRC-RP-91-188, Generic SAR Chapter 3, Site Characteristics (1991)

9. ICRP Publ. 30, Limits for Intakes of Radionuclides by Workers (ICRP, 1988)

10. See for example Cronkite \& Bond, US Armed Forces Medical Journal, Vol.9, p313 (1958)

11. Health Effect of Exposure to Low Level of Ionizing Radiation, BEIR V (NAS/NRC, 1990)

12. G.T. Medford, J.H. Holderness, \& A.B. Crawford, "Multidimensional Uncertainty Propagation of Process Event Trees (MUPPET)", Proceedings of 3rd Annual Safety Analysis Workshop, p67 (EFCOG, 1993)

13. See for example, J.C. Helton \& R.J. Breeding, "Calculation of Reactor Accident Safety Goals", Reliability Eng. \& System Safety, Vol. 39, p129 (1993) 


\section{TABLE I}

\section{Individual Dose Summary}

\begin{tabular}{|c|c|c|c|c|c|}
\hline & Event/Sequence & $\frac{\text { Frequency }}{(\text { /yr })}$ & $\frac{\text { MID-CEDE }}{\text { (rem) }}$ & $\begin{array}{l}\text { Site Boundary } \\
\text { Acute Dose (rem) }\end{array}$ & $\begin{array}{l}10 \text { Mile Averag } \\
\text { CEDE (rem) }\end{array}$ \\
\hline 1 & Rupture/Leak & $2.4(-4)$ & $1.7(-3)$ & $1.0(-3)$ & $8.5(-6)$ \\
\hline 2 & N2 Line Breach & $5.3(-6)$ & $1.4(-9)$ & $8.4(-10)$ & $7.0(-12)$ \\
\hline 3 & Confinement Failure & $3.0(-2)$ & $8.4(-6)$ & $5.0(-6)$ & $4.2(-8)$ \\
\hline 4 & $\begin{array}{l}\text { Vessel Leak During } \\
\text { Maintenance }\end{array}$ & $6.0(-4)$ & $1.4(-5)$ & $8.4(-6)$ & $7.0(-8)$ \\
\hline 5 & $\begin{array}{l}\text { Deflagration During } \\
\text { Maintenance }\end{array}$ & $3.9(-6)$ & $3.4(-1)$ & $2.0(-1)$ & $1.7(-3)$ \\
\hline 6 & Fire wi:h GB Breach & $5.2(-3)$ & $6.4(-8)$ & $3.8(-8)$ & $3.2(-10)$ \\
\hline 7 & Design Basis Tornado & $1.1(-6)$ & $2.0(-7)$ & $1.2(-7)$ & $1.0(-9)$ \\
\hline 8 & Earthquake & & & & \\
\hline & A & $2.0(-4)$ & $3.1(-3)$ & $1.9(-3)$ & $1.6(-5)$ \\
\hline & B & $2.0(-5)$ & $2.9(-1)$ & $1.7(-1)$ & $1.5(-3)$ \\
\hline & $\mathrm{Cl}$ & $2.0(-5)$ & $8.5(-2)$ & $5.1(-2)$ & $4.3(-4)$ \\
\hline & $\mathrm{C} 2$ & $2.0(-5)$ & $1.8(+0)$ & $1.1(+0)$ & $9.0(-3)$ \\
\hline & D1 & $2.0(-6)$ & $2.6(-1)$ & $1.6(-1)$ & $1.3(-3)$ \\
\hline & D2 & $2.0(-6)$ & $1.9(+0)$ & $1.1(+0)$ & $9.5(-3)$ \\
\hline & D3 & $2.0(-7)$ & $1.9(+0)$ & $1.1(+0)$ & $9.5(-3)$ \\
\hline & E1 & $1.2(-6)$ & $4.9(-3)$ & $2.9(-3)$ & $2.5(-5)$ \\
\hline & E2 & $9.4(-9)$ & $4.3(-3)$ & $2.6(-3)$ & $2.2(-5)$ \\
\hline & F1 & $1.2(-7)$ & $1.9(+0)$ & $1.1(+0)$ & $9.5(-3)$ \\
\hline & F2 & $1.2(-7)$ & $3.7(+0)$ & $2.1(+0)$ & $1.9(-2)$ \\
\hline & F3 & $9.4(-10)$ & $1.2(+0)$ & $7.2(-1)$ & $6.0(-3)$ \\
\hline & G1 & $1.2(-8)$ & $2.2(+0)$ & $1.3(+0)$ & $1.1(-2)$ \\
\hline & $\mathbf{G} 2$ & $1.2(-9)$ & $3.7(+0)$ & $2.1(+0)$ & $1.9(-2)$ \\
\hline & G3 & $9.4(-11)$ & $1.5(+0)$ & $9.0(-1)$ & $7.5(-3)$ \\
\hline & HI & $4.8(-7)$ & $7.1(-3)$ & $4.3(-3)$ & $3.6(-5)$ \\
\hline & $\mathrm{H} 2$ & $7.8(-9)$ & $9.5(-3)$ & $5.7(-3)$ & $4.8(-5)$ \\
\hline & I1 & $4.8(-8)$ & $4.0(+0)$ & $2.4(+0)$ & $2.0(-2)$ \\
\hline & 12 & $4.8(-9)$ & $5.8(+0)$ & $3.5(+0)$ & $2.9(-2)$ \\
\hline & 13 & $7.7(-11)$ & $6.5(+0)$ & $3.9(+0)$ & $3.3(-2)$ \\
\hline & J1 & $4.8(-.8)$ & $7.3(-1)$ & $4.4(-1)$ & $3.7(-3)$ \\
\hline & J2 & $4.8(* 10)$ & $4.4(-1)$ & $2.6(-1)$ & $2.2(-3)$ \\
\hline & J3 & $4.8(-11)$ & $2.5(+0)$ & $1.5(+0)$ & $1.3(-2)$ \\
\hline & $\mathbf{K} \mathbf{1}$ & $2.8(-9)$ & $4.3(+0)$ & $2.6(+0)$ & $2.2(-2)$ \\
\hline & K2 & $2.8(-10)$ & $5.8(+0)$ & $3.5(+0)$ & $2.9(-2)$ \\
\hline 9 & $\begin{array}{l}\text { STCS Single Point } \\
\text { Failure }\end{array}$ & $2.0(-6)$ & $1.7(+0)$ & $1.0(+0)$ & $8.5(-3)$ \\
\hline 10 & Normal Operation & 1.0 & $2.2(-7)$ & NA & $1.1(-7)$ \\
\hline
\end{tabular}


TABLE II

Orf-site Population and Meteorology Data Base

\begin{tabular}{rrrrr} 
SECTOR & $\begin{array}{rrrr}\mathbf{5 - 1 0} \text { Mile } \\
\boldsymbol{\chi} / \mathbf{Q}\end{array}$ & $\begin{array}{r}\text { 5-10 Mile } \\
\text { Population }\end{array}$ & $\begin{array}{r}\text { 10-20 Mile } \\
\boldsymbol{x / Q}\end{array}$ & $\begin{array}{r}\text { 10-20 Mile } \\
\text { Population }\end{array}$ \\
\hline S & & & & 50 \\
SSW & 2.48 & 8 & 1.08 & 65 \\
SW & 3.69 & 7 & 1.60 & 109 \\
WSW & 5.79 & 6 & 2.50 & 167 \\
W & 4.62 & 7 & 2.04 & 145 \\
WNW & 3.73 & 170 & 1.81 & 683 \\
NW & 3.17 & 856 & 1.52 & 2329 \\
NNW & 3.83 & 135 & 1.59 & 4381 \\
N & 5.77 & 1580 & 2.35 & 1301 \\
NNE & 4.62 & 21 & 2.11 & 69 \\
NE & 4.88 & 46 & 2.24 & 299 \\
ENE & 4.76 & 56 & 2.29 & 779 \\
E & 4.67 & 21 & 2.28 & 1231 \\
ESE & 4.39 & 5 & 1.93 & 440 \\
SE & 4.32 & 0 & 1.87 & 92 \\
SSE & 2.84 & 0 & 1.23 & 139
\end{tabular}

NOTE: The unit of $\chi / Q$ is $10^{-8} \mathrm{sec} / \mathrm{m}^{3}$ 
TABLE III

P(>D) for Prompt Fatality

Acute Dose at Site Events \# $\quad$ Frequency (/yr) P

Boundary (rem)

$\begin{array}{llll}3.9(+0) & \text { I3 } & 7.7(-11) & 7.7(-11) \\ 3.5(+0) & \text { I2+K2 } & 5.1(-9) & 5.2(-9) \\ 2.6(+0) & \text { K1 } & 2.8(-9) & 8.0(-9) \\ 2.4(+0) & \text { I1 } & 4.8(-8) & 5.6(-8) \\ 2.1(+0) & \text { F2+G2 } & 1.2(-7) & 1.8(-7) \\ 1.5(+0) & \text { J3 } & 4.8(-11) & 1.8(-7) \\ 1.3(+0) & \text { G1 } & 1.2(-8) & 1.9(-7) \\ 1.1(+0) & \text { C2+D2+D3+F1 } & 2.2(-5) & 2.2(-5) \\ 1.0(+0) & 9 & 2.0(-6) & 2.4(-5) \\ 9.0(-1) & \text { G3 } & 9.4(-11) & 2.4(-5) \\ 7.2(-1) & \text { F3 } & 9.4(-10) & 2.4(-5) \\ 4.4(-1) & \text { J1 } & 4.8(-8) & 2.4(-5) \\ 2.6(-1) & \text { J2 } & 4.8(-10) & 2.4(-5) \\ 2.0(-1) & 5 & 3.9(-6) & 2.8(-5) \\ 1.7(-1) & \text { B } & 2.0(-5) & 4.8(-5) \\ 1.6(-1) & \text { D1 } & 2.0(-6) & 5.0(-5) \\ 5.1(-2) & \text { C1 } & 2.0(-5) & 7.0(-5) \\ 5.7(-3) & \text { H2 } & 7.8(-9) & 7.0(-5) \\ 4.3(-3) & \text { H1 } & 4.8(-7) & 7.0(-5) \\ 2.9(-3) & \text { E1 } & 1.2(-6) & 7.1(-5) \\ 2.6(-3) & \text { E2 } & 9.4(-9) & 7.1(-5) \\ 1.9(-3) & \text { A } & 2.0(-4) & 2.7(-4) \\ 1.0(-3) & 1 & 2.4(-4) & 5.1(-4)\end{array}$

Note: $2.0(-3)=2.0 \times 10^{-3}$ 
TABLE IV

P(>D) for Cancer Fatality

\begin{tabular}{|c|c|c|c|}
\hline $\begin{array}{l}10 \text { Mile Average } \\
\text { CEDE(rem) }\end{array}$ & Events \# & Frequency (/yr) & $\underline{\mathbf{P}(>\mathbf{D})}$ \\
\hline $3.3(-2)$ & 13 & $7.7(-11)$ & $7.7(-11)$ \\
\hline $2.9(-2)$ & $\mathrm{I} 2+\mathrm{K} 2$ & $5.1(-9)$ & $5.2(-9)$ \\
\hline $2.2(-2)$ & K1 & $2.8(-9)$ & $8.0(-9)$ \\
\hline $2.0(-2)$ & II & $4.8(-8)$ & $5.6(-8)$ \\
\hline $1.9(-2)$ & $\mathrm{F} 2+\mathrm{G} 2$ & $1.2(-7)$ & $1.8(-7)$ \\
\hline $1.3(-2)$ & J3 & $4.8(-11)$ & $1.8(-7)$ \\
\hline $1.1(-2)$ & G1 & $1.2(-8)$ & $1.9(-7)$ \\
\hline $9.5(-3)$ & $\mathrm{D} 2+\mathrm{D} 3+\mathrm{F} 1$ & $2.3(-6)$ & $2.5(-6)$ \\
\hline $9.0(-3)$ & $\mathrm{C} 2$ & $2.0(-5)$ & $2.2(-5)$ \\
\hline $8.5(-3)$ & 9 & $2.0(-6)$ & $2.4(-5)$ \\
\hline $7.5(-3)$ & G3 & $9.4(-11)$ & $2.4(-5)$ \\
\hline $6.0(-3)$ & F3 & $9.4(-10)$ & $2.4(-5)$ \\
\hline $3.7(-3)$ & $\mathbf{J} 1$ & $4.8(-8)$ & $2.4(-5)$ \\
\hline $2.2(\cdot .3)$ & $\mathrm{J} 2$ & $4.8(-10)$ & $2.4(-5)$ \\
\hline $1.7(-3)$ & 5 & $3.9(-6)$ & $2.8(-5)$ \\
\hline $1.5(-3)$ & B & $2.0(-5)$ & $4.8(-5)$ \\
\hline $1.3(-3)$ & D1 & $2.0(-6)$ & $5.0(-5)$ \\
\hline $4.3(-4)$ & $\mathrm{Cl}$ & $2.0(-5)$ & $7.0(-5)$ \\
\hline $4.8(-5)$ & $\mathrm{H} 2$ & $7.8(-9)$ & $7.0(-5)$ \\
\hline $3.6(-5)$ & H1 & $4.8(-7)$ & $7.0(-5)$ \\
\hline $2.5(-5)$ & El & $1.2(-6)$ & $7.1(-5)$ \\
\hline $2.2(-5)$ & E2 & $9.4(-9)$ & $7.1(-5)$ \\
\hline $1.6(-5)$ & $\mathbf{A}$ & $2.0(-4)$ & $2.7(-4)$ \\
\hline $8.5(-6)$ & 1 & $2.4(-4)$ & $5.1(-4)$ \\
\hline $1.1(-7)$ & 10 & $1.0(+0)$ & $1.0(+0)$ \\
\hline
\end{tabular}

Note: $2.0(-3)=2.0 \times 10^{-3}$ 
FIGURE 1

PROMPT FATALITY

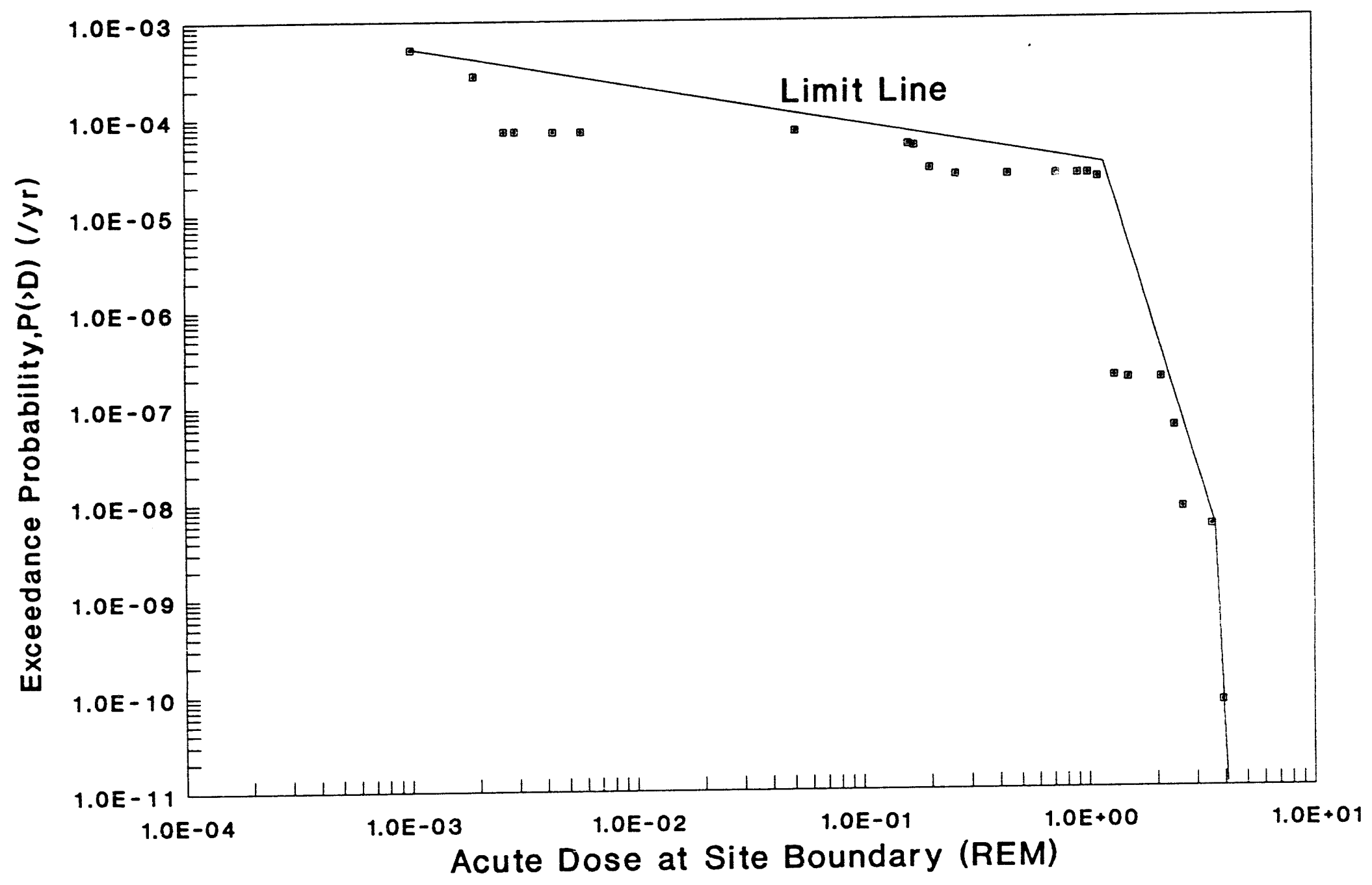


FIGURE 2

CANCER FATALITY

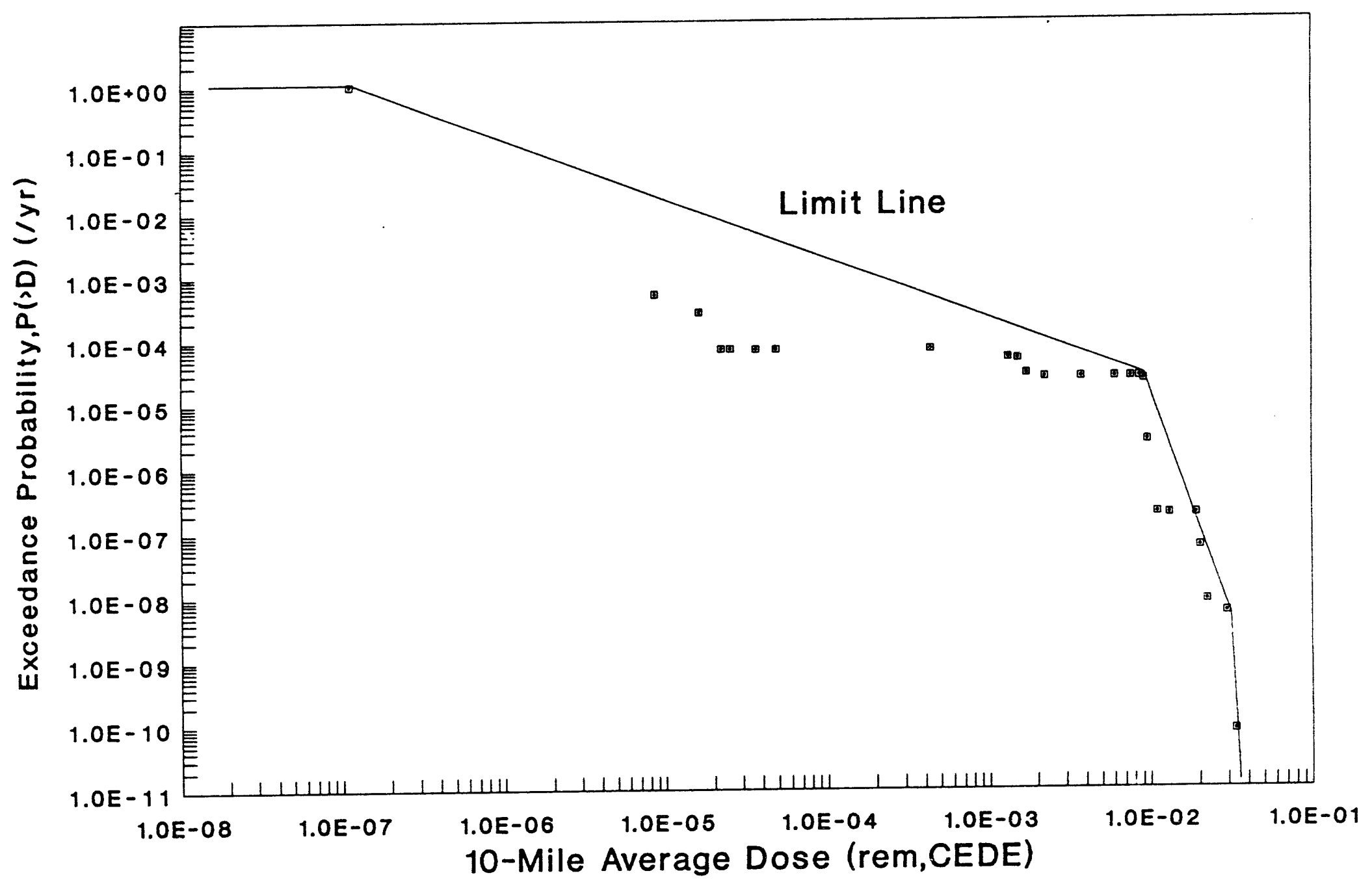




\section{DISTRIBUTION}

Bradley, R.F. 992-2W

Cappucci, A.J. 992-1W

Dickey, B.R. 992-4W

Durant, W.S. 992-1W

Ebra-Lima, O.M. 703-F

Hitchler, M.J. 992-1W

Moore, M.L. 773-A

O'Block, V.S. 992-2W

Paddleford, D.F. 992-1W

Ridgely, G.C. 992-2W

Satterfield, R.M. 719-4A

Schornhorst, J.R. 992-1 W

Skwarek, R.J. 992-4W

Taylor, K. 992-4W

Wooten, L.A. 992-4W

FSES File, 992-2W

Anderson, J.E. 703-47A

Smartt, J.A. 703-47A
Burns, R.B. 992-4W

Cowen, M.L. 992-1W

Domer, J.A. 992-2W

East, J.M. 992-1 W

Felak, D.D. 703-A

McFarlane, A.F. 992-4W

Myers, L.B. 235-H

O'Kula, K.R. 992-1W

Rankin, D.B. 704-C

Salymeh, S.R. 992-1W

Savani, N.K. 992-1W

Sharp, D.A. 992-1W

Stephens, K.W. 992-4W

Waltz, W.R. 992-2W

Kim, K.S. 992-2W (20)

Document/Record Admin, 773-42A (5)

Schuler, C.F. 703-47A

Spears, T.J. 703-47A 

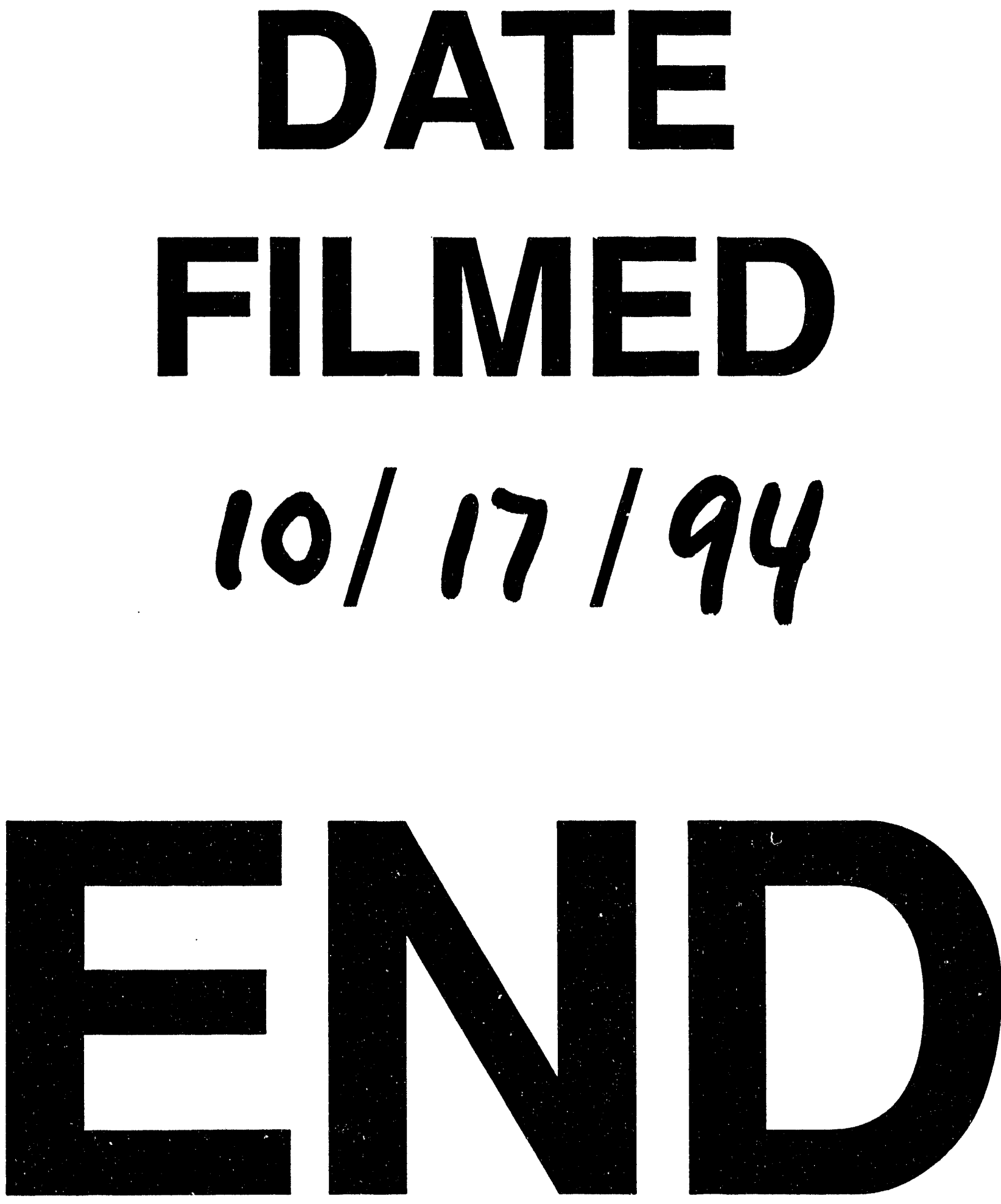
